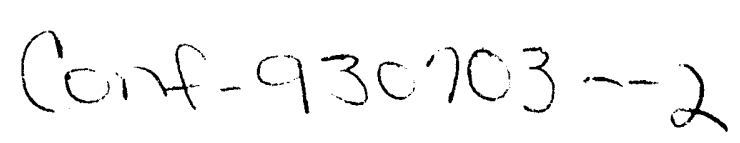

LA-UR- 93-2415

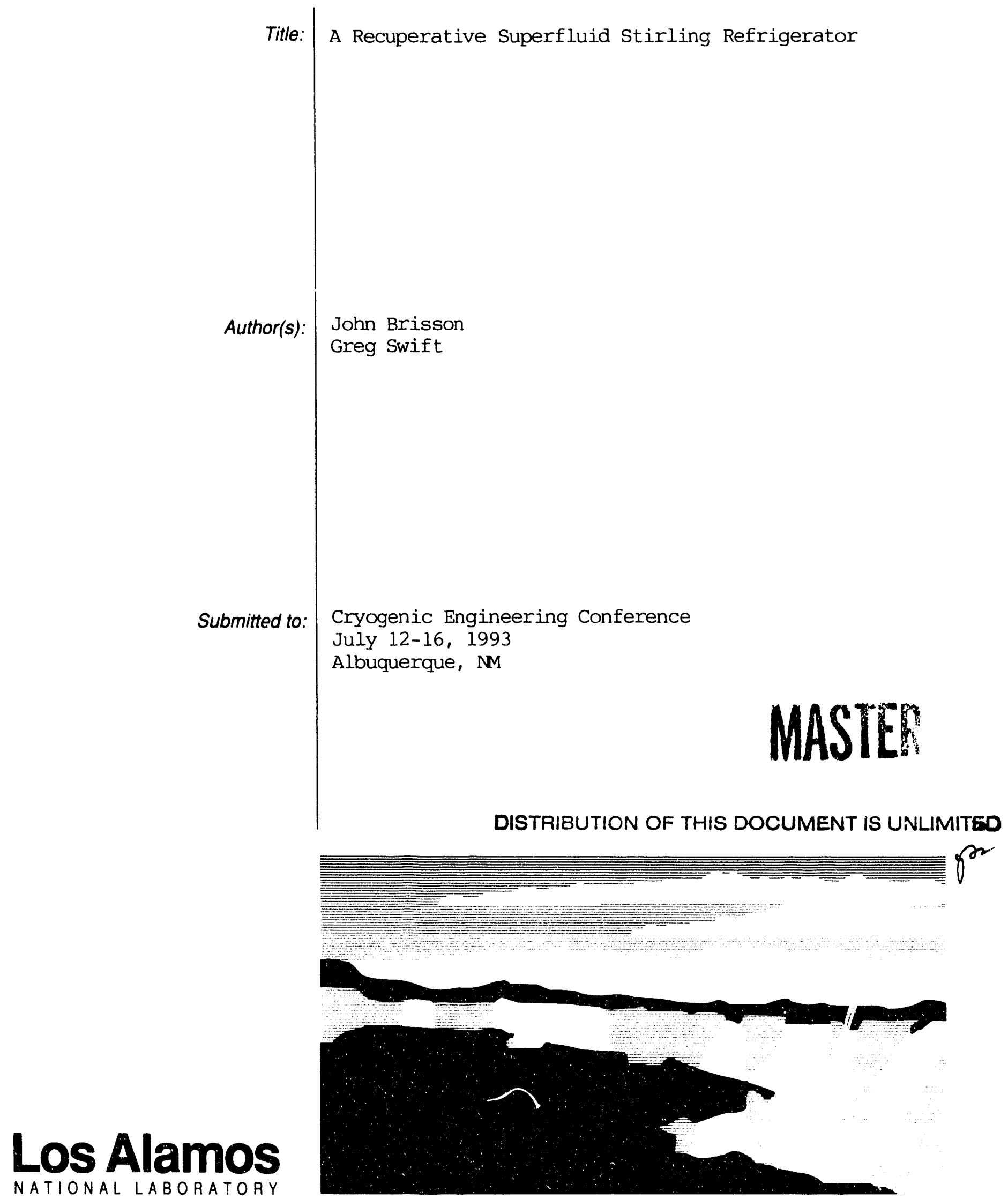

Los Alamos National Laboratory, an affirmative action/equal opportunity emplóyer, is operated by the University of California for the U.S. Department of Enercy under contract W-7405-ENG-36. By acceptance of this article, the publisher recognizes that the U.S. Government retains a nonexclusive, royalty-free license to publish or reproduce the published form of this contribution, or to allow others to do so, for U.S. Government purposes. The Los Alamos National Laboratory requests that the publisher identify this article as work performed under the auspices of the U.S. Department of Energy. 


\title{
A RECUPERATIVE SUPERFLUID STIRLING REFRIGERATOR
}

\author{
J. G. Brisson and G.W. Swift \\ Condensed Matter and Thermal Physics Group \\ Los Alamos National Laboratory \\ Los Alamos, New Mexico 87545
}

\begin{abstract}
A superfluid Stirling refrigerator has been built with a counterflow heat exchanger serving as a recuperative regenerator. It has achieved temperatures of $296 \mathrm{mK}$ with a $4 \%$ ${ }^{3} \mathrm{He}-{ }^{4} \mathrm{He}$ mixture. Cooling power versus temperature and speed is presented for a $6.6 \%$ mixture.
\end{abstract}

\section{INTRODUCTION}

The superfluid Stirling refrigerator (SSR) uses a ${ }^{3} \mathrm{He}-{ }^{4} \mathrm{He}$ liquid mixture as a working fluid. It operates at temperatures below $2 \mathrm{~K}$ where the ${ }^{4} \mathrm{He}$ component of the working fluid is superfluid. The ${ }^{3} \mathrm{He}$ component of the working fluid, to first approximation, behaves thermodynamically like an ideal gas in the inert background of superfluid ${ }^{4} \mathrm{He} .{ }^{1}$ Using pistons equipped with a superleak bypass, it is possible to expand and compress the ${ }^{3} \mathrm{He}$ solute "gas" alone. The SSR is a Stirling machine equipped with these "superleaked" pistons to take advantage of the properties of the ${ }^{3} \mathrm{He}$ solute to cool below $1 \mathrm{~K}$. The proof of principle was shown by Kotsubo and Swift in 1990.2,3

There are three other techniques for cooling below $1 \mathrm{~K}:$ 1) the ${ }^{3} \mathrm{He}-{ }^{4} \mathrm{He}$ dilution refrigerator which utilizes the endothermic heat of mixing of ${ }^{3} \mathrm{He}$ into ${ }^{4} \mathrm{He}$ to reach temperatures below $0.010 \mathrm{~K} ; 2$ ) the evaporation of ${ }^{3} \mathrm{He}$ which can reach temperatures of 0.3 $\mathrm{K}$; and, 3) adiabatic demagnetization of a paramagnetic salt. There are severai advantages of the SSR over each of the other techniques. The power consumption of a dilution refrigerator is typically on the order of kilowatts; whereas, the SSR consumes tens to hundreds of watts. The SSR has the potential to cool well below $0.3 \mathrm{~K}$ and out perform the evaporative ${ }^{3} \mathrm{He}$ refrigerator. Adiabatic demagnetization often requires magnetic shielding between the refrigerator and the object to be cooled; obviously, the SSR requires no such shielding. The dilution refrigerator and the evaporative ${ }^{3} \mathrm{He}$ refrigerator are not naturally suited to a zero gravity environment, whereas the SSR is unaffected by zero G.

\section{DESIGN AND CONSTRUCTION}

A diagram of our refrigerator is shown in Fig. 1. This refrigerator is actually two SSR's operating 180 derrees out of phase with each other which allows the use of a counterflow 


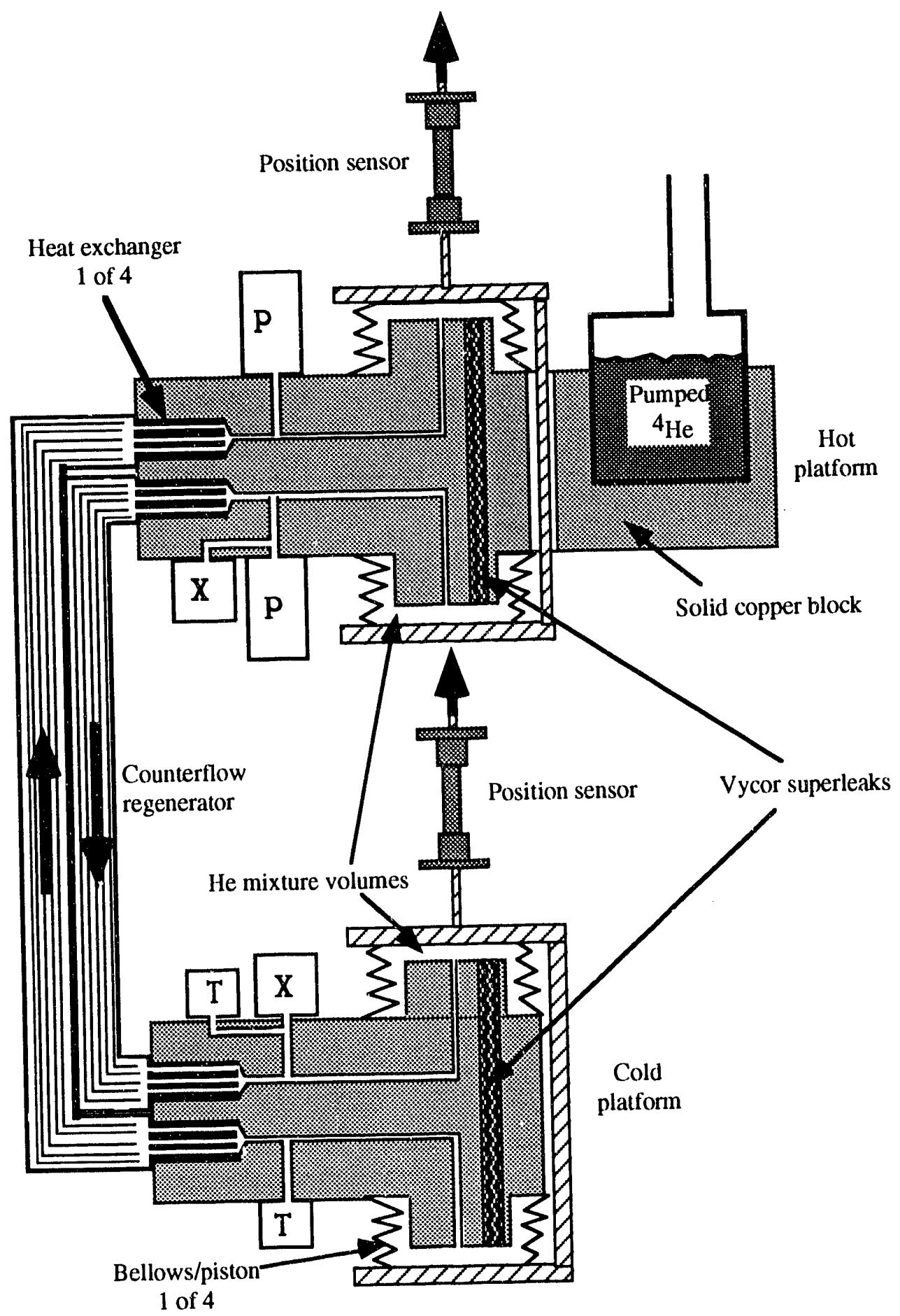

Figure 1. The SSR. Pressure gauges are delineated with a "P", concentration gauges with an " $\mathrm{X}$ " and thermometers with a" $\mathrm{T}$ ". The calibrated germanium thermometer and the cold platform heater, which are mounted on the cold platform, are not shown. The heavy arrows show fluid flow direction in the regenerator corresponding to the piston motion direction shown at the position sensors. The moving parts are shown with widely-spaced crosshatching.

heat exchanger to act as a regenerator for each of the SSR's . Our counterflow regenerator, or recuperator, consists of a total of $2380.305 \mathrm{~mm}$ O.D. CuNi tubes with $0.038 \mathrm{~mm}$ walls. These tubes are silver soldered in a hexagonally close packed array with alternating rows corresponding to each "half" of the SSR. We use silver solder to insure that the solder does not become a superconductor at our operating temperatures and spoil the thermal conduction between the lubes. The length of the regenerator is apprnximately $20 \mathrm{~cm}$. 
The pistons are made with welded bellows ${ }^{4}$ which have convolutions that nest into one another to minimize the dead volume. The hot platform pistons, held at $1.2 \mathrm{~K}$ by the pumped ${ }^{4} \mathrm{He}$ pot, are rigidly connected together and driven sinusoidally by a rigid push rod from a room temperature drive. The cold platform pistons are similarly driven.

The hot pistons' stroke is $5.8 \mathrm{~mm}$ corresponding to a swept volume of $1.85 \mathrm{~cm}^{3}$. The cold pistons' stroke is $5.0 \mathrm{~mm}$ corresponding to a swept volume of $1.6 \mathrm{~cm}^{3}$. The total volume of liquid in the refrigerator is $14.3 \mathrm{~cm}^{3}$.

The superleaks shown in Fig. 1 are cylinders of Vycor glass approximately $3.6 \mathrm{~mm}$ in diameter and $7.4 \mathrm{~cm}$ long. These allow the superfluid ${ }^{4} \mathrm{He}$ to freely flow between the halves of the refrigerator during its operation.

The heat exchangers are copper cylinders press fit into the large copper blocks on which the pistons are mounted. The hot platform heat exchangers are $1.14 \mathrm{~cm}$ long with four $0.8 \mathrm{~mm}$ diameter holes drilled longitudinally through the cylinder. The low temperature heat exchangers are $1.14 \mathrm{~cm}$ long with $120.51 \mathrm{~mm}$ diameter holes.

The pressure gauges are of the flexible diaphragm type described by Straty and Adams. ${ }^{5}$ The concentration gauges are coaxial capacitors where the ${ }^{3} \mathrm{He}$ concentration is obtained from the dielectric constant of the mixture. 6 The thermometers shown in Fig. 1 are intended to measure the heating/cooling due to the adiabatic compression/expansion of the ${ }^{3} \mathrm{He}$. They are made by suspending a chip of carbon made from a $220 \mathrm{ohm}$ Speer resistor on thin manganin wires inside a hollow Stycast 1266 envelope. The helium mixture is admitted into the Stycast chamber through a $0.8 \mathrm{~mm}$ diameter capillary.

The linear position sensors are mounted at $1 \mathrm{~K}$ to monitor the positions of the pistons in situ. The position sensor consists of two counter wound copper coils on a thin walled stainless steel tube. A pick-up coil wound on a ground stainless steel rod rides inside the counterwound coils. We generally drive the outer coils with a $1 \mathrm{~mA} 1 \mathrm{kHz}$ signal and monitor the output voltage of the pick-up coil as a measure of position. The resolution of this system is better than $0.025 \mathrm{~mm}$.

The two fill lines into each of the SSR halves are sealed with low temperature pneumatic valves mounted on the pumped helium platform. These valves are actuated using pressurized ${ }^{4} \mathrm{He}$. If we did not use these valves, operation of the SSR would cause the mixture to oscillate up and down the fill capillaries and put a significant heat load on the refrigerator.

A calibrated germanium resistance thermometer ${ }^{7}$ is mounted on the outside of the cold platform to monitor the temperature while a $220 \mathrm{ohm}$ Speer resistor is used to monitor the temperature of the hot platform.

Further details of construction can be found elsewhere. 8

\section{PROCEDURE AND RESULTS}

The refrigerator was cooled to $1.2 \mathrm{~K}$ and loaded with a $4 \%{ }^{3} \mathrm{He}-{ }^{4} \mathrm{He}$ mixture. The pneumatic valves were closed and the refrigerator was operated at various speeds to find a minimum temperature of $296 \mathrm{mK}$ at a speed of 1 cycle every 43 seconds.

We then reloaded the refrigerator with $6.6 \%{ }^{3} \mathrm{He}-{ }^{4} \mathrm{He}$ mixture and measured the cooling power as function of temperature and operating speed. This was done by actively temperature controlling the cold platform for a chosen temperature and speed for at least 15 minutes to allow the refrigerator to come to steady state. We then averaged the heat delivered to the cold platform heater over 10 cycles to determine the average cooling power of the SSR. The cooling powers are shown in Fig. 2 for three operating speeds of 1 cycle every 19,27 , and 45 seconds for temperatures between 0.3 and $1.1 \mathrm{~K}$.

\section{DISCUSSION}

Figure 2 shows that there is an optimal operating speed at each temperature to maximize cooling power. Thus the maximum cooling power curve for an SSR consists of the upper envelope of the lines we show in Fig. 2. 


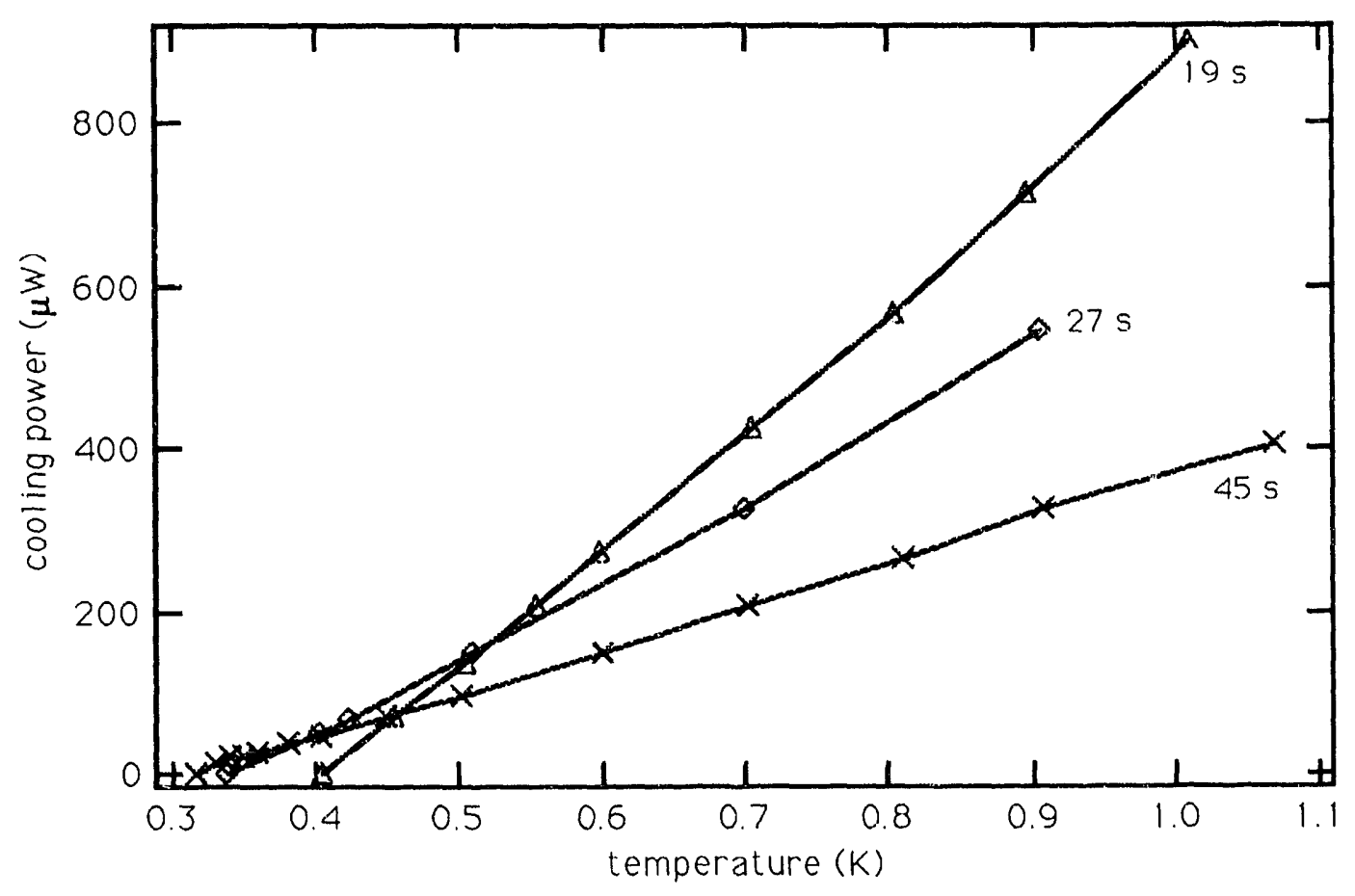

Figure 2. Plots of cooling power versus temperature for the SSR. Each curve corresponds to a fixed operating speed and is labeled with the time necessary for the SSR to complete one cycle.

We could not stably operate the refrigerator at speeds higher than $19 \mathrm{~s}$ per cycle since the critical velocity of the ${ }^{4} \mathrm{He}$ in the superleaks would be exceeded. This results in the rapid warming of the refrigerator and large pressure oscillations in the SSR due to the compression of the ${ }^{4} \mathrm{He}$. A higher speed refrigerator would require larger superleaks.

The SSR's reduction in cooling power at low temperature is due to the redistribution of the ${ }^{3} \mathrm{He}$ in the refrigerator and the effectiveness of the recuperator. This distribution is affected by both the fountain pressure in the warm end ${ }^{8}$ and the Fermi gas hehavior of the ${ }^{3} \mathrm{He}$ in the cold end.

It is of interest to estimate of the Fermi temperature of the ${ }^{3} \mathrm{He}$ in the cold piston when the SSR is operating at $320 \mathrm{mK}$. For the sake of simplicity we assume that the fountain pressure in the hot piston is negligible and that the ${ }^{3} \mathrm{He}$ behaves as an ideal Boltzmann gas throughout the refrigerator. We assume that the volume of the regenerator is negligible and that the volumes of the hot and cold pistons are the same. Under these assumptions it is easy to show that $X_{c}=2 X_{a v} /\left(1+T_{c} / T_{h}\right)$ where $X_{c}$ is the concentration in the cold piston, $X_{a v}$ is the average concentration in the refrigerator, $T_{c}$ is the cold piston temperature, and $\mathrm{T}_{\mathrm{h}}$ is the hot piston temperature. In our refrigerator $\mathrm{T}_{\mathrm{h}}$ is $1.2 \mathrm{~K} ; \mathrm{T}_{\mathrm{c}}$ is $0.32 \mathrm{~K}$; and, $\mathrm{X}_{\mathrm{av}}$ is $6.6 \%$. Using our equation we find $\mathrm{X}_{\mathrm{c}}$ is $10.4 \%$. This corresponds to a Ferrrij temperature of $540 \mathrm{mK}$. Clearly, this SSR is operating with a Fermi gas in the cold pistons and that a proper analysis of this refrigerator will require considerating the Fermi gas' thermodynamic properties. It is interesting to note that a $10.4 \%$ solution phase separates at $240 \mathrm{mK} .{ }^{9}$

\section{CONCLUSIONS AND FUTURE WORK}

We have built a superfluid Stirling refrigerator capable of reaching temperatures of 296 $\mathrm{mK}$. The cooling power is linear with temperature at a fixed speed. The single stage Stirling refrigerator can achieve all temperatures obtainable with a continuous evaporative ${ }^{3} \mathrm{He}$ refrigerator.

In the future, we plan to investigate the contibution of the Fermi nature of the ${ }^{3} \mathrm{He}$ to the cooling power at low temperatures and to investigate the contribution of the phononroton gas to the cooling power above $1 \mathrm{~K}$. An improved recuperator should lower the ultimate temperature reached by a singic stagc $33 R$. Multistaged SSRs wil! a!low futher 
reductions in temperature. A pulse tube version 10 of these refrigerators will be the first step towards the elimination of moving parts of this refrigerator.

\section{REFERENCES}

1. J. Wilks. "The Properties of Liquid and Solid Helium," Clarendon, Oxford (1967) P. 232.

2. V. Kotsubo and G.W. Swift, Superfluid Stirling refrigerator: a new method for cooling below 1 Kelvin, in: "Proceedings of the Sixth International Cryocoolers Conference", Geoffrey Green and Margaret Knox, ed., David Taylor Research Center, Bethesda, Md (1991).

3. V. Kotsubo and G.W. Swift, Superflud Stirling-cycle refrigeration below 1 Kelvin, J. Low Temp. Phys. 83:217 (1991).

4 Type 60030-1 from Metal Bellows Corporation, Sharon, Mass.

5. G.C. Straty and E.D. Adams, Highly sensitive capacitive pressure gauge, Rev. Sci. Instrum. 40:1393 (1969).

6. H. A. Kierstead, Dielectric constant, molar volume, and phase diagram of saturated liquid ${ }^{3} \mathrm{He}-{ }^{4} \mathrm{He}$ mixtures, J. Low Temp. Phys 24:497 (1976).

7. Lakeshore Cryotronics, Inc. 64 E. Walnut St. Westerville, Ohio 43081.

8. J.G. Brisson and G.W. Swift, Superfluid Stirling refrigerator with a counterflow regenerator, in: "Proceedings of the Seventh International Cryocoolers Conference", Santa Fe, NM (1992).

9. R. Radebaugh, Thermodynamic properties of ${ }^{3} \mathrm{He}-{ }^{4} \mathrm{He}$ solutions with applications to the ${ }^{3} \mathrm{He}-{ }^{4} \mathrm{He}$ dilution refrigerator, NBS tech note $362: 19$ (1967).

10. R. Radebaugh, "A review of pulse tube refrigeration", Adv. Cryogenic Eng., 35:1191 (1990).

\section{DISCLAIMER}

\footnotetext{
This report was prepared as an account of work sponsored by an agency of the United States Government. Neither the United States Government nor any agency thereof, nor any of their employees, makes any warranty, express or implied, or assumes any legal liability or responsibility for the accuracy, completeness, or usefulness of any information, apparatus, product, or process disclosed, or represents that its use would not infringe privately owned rights. Reference herein to any specific commercial product, process, or service by trade name, trademark, manufacturer, or otherwise does not necessarily constitute or imply its endorsement, recommendation, or favoring by the United States Government or any agency thereof. The views and opinions of authors expressed herein do not necessarily state or reflect those of the United States Government or any agency thereof.
} 

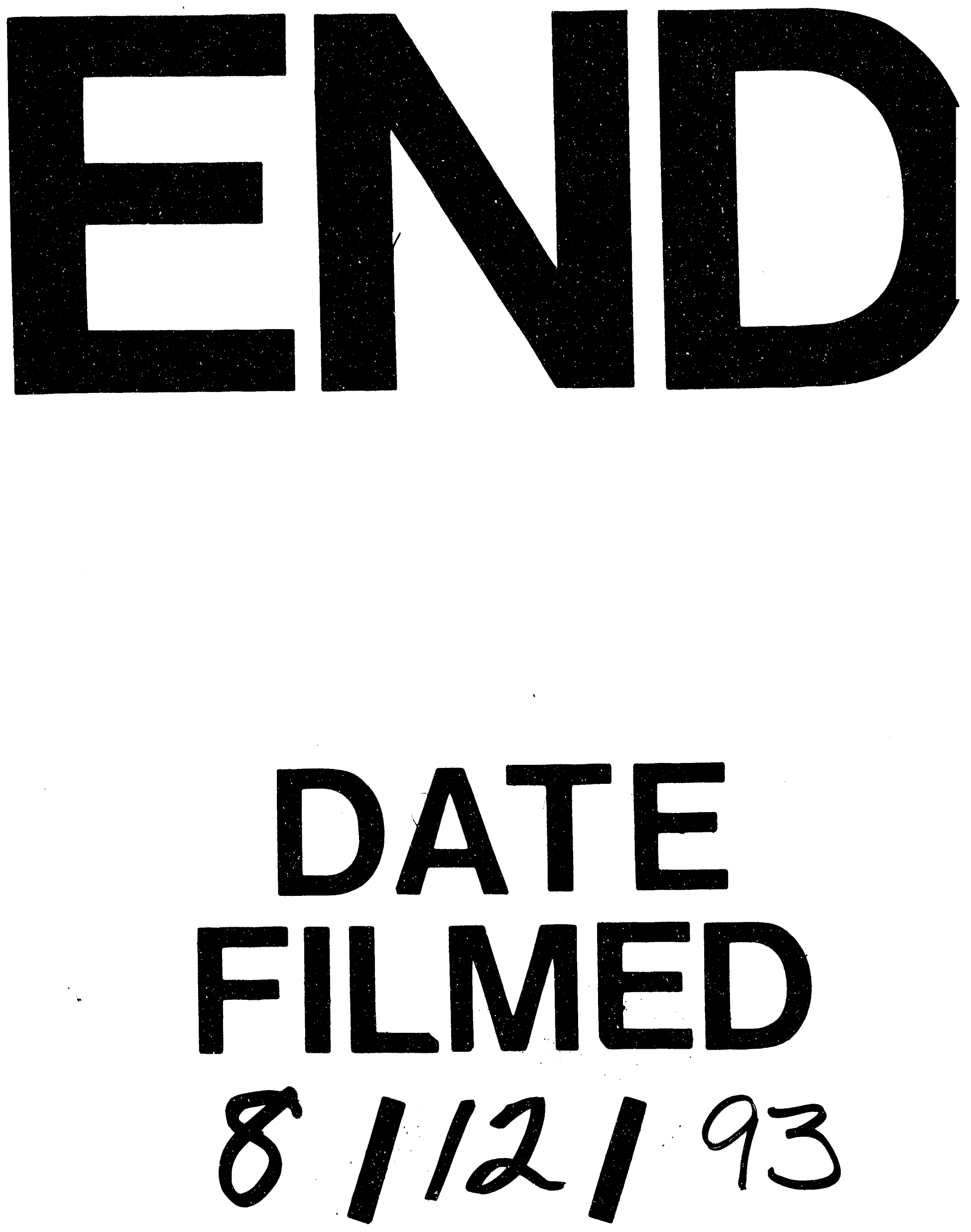
